\title{
Imposex levels and tributyltin pollution in Ria de Aveiro (NW Portugal) between 1997 and 2007: evaluation of legislation effectiveness
}

\author{
Susana Galante-Oliveira, ${ }^{* a}$ Isabel Oliveira ${ }^{a}{ }^{\text {Niels Jonkers, }}{ }^{b}$ William J. Langston, ${ }^{c}$ Mário Pacheco ${ }^{a}$ \\ and Carlos M. Barroso ${ }^{a}$
}

\author{
Received 15th January 2009, Accepted 6th May 2009 \\ First published as an Advance Article on the web 2nd June 2009 \\ DOI: $10.1039 / \mathrm{b} 900723 \mathrm{~g}$
}

\begin{abstract}
Nucella lapillus imposex levels and organotin (OT) concentrations in water and female tissues were measured in samples collected from the Ria de Aveiro (NW Portugal) between 1997 and 2007. Vas deferens sequence index (VDSI), relative penis size index (RPSI), mean female penis length (FPL) and percentage of imposex affected females $(\% I)$ were used to determine imposex levels at each site. A significant temporal decline in imposex intensity was observed during the assessed period. Imposex decrease was evident after 2003 although improvements were most notable from 2005 to 2007, probably due to the implementation of the EU Council Regulation no.782/2003 forbidding further application of tributyltin (TBT) antifouling on vessels carrying EU flags. Despite these improvements, OT analysis in $N$. lapillus female tissues and water indicate there are still recent TBT inputs into the study area.
\end{abstract}

\section{Introduction}

Environmental concern about organotin (OT) compounds has increased strongly due to the worldwide use of tributyltin (TBT), since the mid 1960s, as a biocide in antifouling paints (AFP) applied to boat hulls and other submerged structures to prevent bioincrustation. ${ }^{1}$ Although it was extremely efficient as a biocide, several harmful effects on non-target organisms were described as a consequence of its intense usage. One of the best documented effects is the disruption of the endocrine and reproductive functions in some prosobranch gastropod molluscs, expressed by the development of imposex - the superimposition of male sexual characters in females. ${ }^{2,3}$ Imposex in the dog-whelk Nucella lapillus (L.) has been intensively used as a biomarker of TBT pollution levels on North Atlantic rocky shores. ${ }^{4}$ In 1998, the use of this species as a bioindicator was recommended in OSPAR Joint Assessment and Monitoring Program (JAMP) guidelines, ${ }^{5}$ mainly due to the species widespread distribution (from northern Russia to southern Portugal), restricted power of dispersion (absence of a planktonic larval phase), limited adult mobility ${ }^{6}$ and high sensitivity to TBT pollution (imposex induction occurs at very low concentrations in water: $\left.<0.5 \mathrm{ng} \mathrm{Sn} 1^{-1}\right){ }^{7}$ During the 1980 s, extreme cases of complete female functional sterilization, population declines and extinctions were among the reported consequences of TBT pollution. ${ }^{\mathbf{8} 9}$

In response to these and other deleterious impacts, the European Council Directive 76/769/EEC was amended by the Directive $89 / 677 /$ EEC that prohibited the use of OT compounds in

${ }^{a}$ CESAM \& Department of Biology, University of Aveiro, 3810-193 Aveiro, Portugal. E-mail: susana.oliveira@ua.pt; Fax: +351 234426408; Tel: +351 234370350 ext. 22752 (LEME)

${ }^{b} I V A M$, University of Amsterdam, 1001 ZB Amsterdam, The Netherlands ${ }^{c}$ Marine Biological Association, Citadel Hill, Plymouth, PL1 2PB, United Kingdom antifouling systems on vessels $<25 \mathrm{~m}$ in length. ${ }^{10}$ This latest Directive was transposed into Portuguese internal law in 1993, but it was insufficient to reduce TBT pollution. ${ }^{11,12}$ In 2001 the International Maritime Organization (IMO) adopted the 'International Convention on the Control of Harmful Antifouling Systems on Ships' (AFS Convention). ${ }^{13}$ This resolution called for a worldwide prohibition on the application of OTs as biocides in AFP on ships by the effective date of 1 January 2003, and a complete banishment by 1 January 2008. However, the Convention could only enter into force, legally, 12 months after 25 States representing $25 \%$ of the world's merchant shipping tonnage had ratified it. Until then, the legal effect of 1 January 2003 would be suspended. Meanwhile, based on the IMO resolution to implement the Convention as a matter of urgency, EU countries banned the marketing and use of OT compounds in antifouling systems under Directive 2002/62/EC. ${ }^{14}$ Subsequently, the EU adopted Regulation no.782/2003, prohibiting the application or re-application of TBT coatings on Member States' national mercantile fleets and on ships operating under their authority, from 1 July $2003 .{ }^{15}$ The AFS Convention entry into force date was finally met on 17 September 2007, with the 25th State ratification, representing a total of $38 \%$ of the world's merchant shipping tonnage. ${ }^{16}$ As a result, the international ban on TBT was scheduled for 17 September 2008. ${ }^{16}$

The current study aims to assess the evolution of TBT pollution in Ria de Aveiro (NW Portugal) between 1997 and 2007 considering the above legislative scenario. This estuarine system has a high economical potential, supporting fishery and aquaculture activities, as well as ports, dockyards and industry facilities. In addition it is classified as a special protected area by the EU nature and biodiversity policy 'Natura 2000 Network'. This identifies the Ria de Aveiro as an ecosystem of considerable importance, ${ }^{17}$ requiring active management of its environmental and ecological quality. 


\section{Materials and methods}

\section{Sampling}

Two sampling strategies were adopted in the current work. One centred on the selection of 4 sampling sites (Sts. 2, 3, 9 and 11; Fig. 1) covering an extensive area from the open coast to inside the estuarine system where TBT potential sources are located (port terminals, dockyards and marinas). These sites were used for the assessment of long-term evolution of imposex, here designated as "Long-term monitoring"; dog-whelks were sampled at these sites in 1997, 2003, 2005, 2006 and 2007 (from June to November) and imposex levels were assessed. The other strategy, designated as "Short-term monitoring", aimed to check if an eventual reduction in imposex levels could be detected within a one-year period and focused on a larger number of sites spread over a widened geographical area of the Ria de Aveiro and its adjacent coast. For that purpose, dog-whelks were sampled in August 2005 and 2006 at Sts. 1-5, 9, 11, 16 and 20 (Fig. 1) for imposex assessment.

Additionally, in order to verify if very recent inputs of TBT still occur in this estuarine system, OTs concentrations were determined in female dog-whelk tissues and water. Animals were collected in August 2006 (Sts. 1-5, 9, 11, 16 and 20) and water samples were obtained in the same period at Sts. 1-23 (Fig. 1). Water collection covered most of the area of Ria de Aveiro to allow a representative image of OTs water contamination: sampling sites were spread across the main channels (including the navigation channel) and the adjacent Atlantic coast. Water sampling was performed twice, with one week interval, on the same lowest-tide level.

\section{Imposex analysis}

$N$. lapillus were collected randomly by hand at each site. The shell height ( $\mathrm{SH}$-length from the apex to the siphonal canal) was measured with vernier callipers to the nearest $0.1 \mathrm{~mm}$. After shell removal, animals were sexed and analysed for imposex without narcotization. The penis length (PL) was measured using a stereo microscope with a graduated eyepiece to the nearest $0.14 \mathrm{~mm}$ and the mean female penis length (FPL) was determined for each sample. The relative penis size index [RPSI = mean female penis length $(\mathrm{FPL})^{3} \times 100 /$ mean male penis length $\left.(\mathrm{MPL})^{3}\right]$, the vas deferens sequence index (VDSI) and the percentage of females affected with imposex $(\% I)$ were also determined for each station according to Gibbs et al. ${ }^{18}$ Parasitized specimens were discarded from the analysis.

\section{Female OT body burdens}

After being examined for imposex, 10-15 female dog-whelks from each site were preserved at $-20{ }^{\circ} \mathrm{C}$ for chemical analysis. TBT and dibutyltin (DBT) were measured by atomic absorption spectroscopy (AAS) in homogenized whole tissues. Although this technique does not perform the complete OTs speciation (of butyl-, phenyl- and octyltins), previous studies have shown that butyltins (BTs) represent the dominant OT fraction in the study area and, of these, TBT is the most abundant compound. ${ }^{19-21}$ Analytical procedures were largely based on those of Ward et $a{ }^{22}$ as modified and described fully by Bryan et $a l .{ }^{8}$ Recoveries of TBT and DBT were $\sim 100$ and $92 \%$ respectively, and were corrected by the use of standard additions in all samples. Detection limits for TBT and DBT were about $10 \mathrm{ng} \mathrm{Sn} \mathrm{g}^{-1} \mathrm{dw}$.

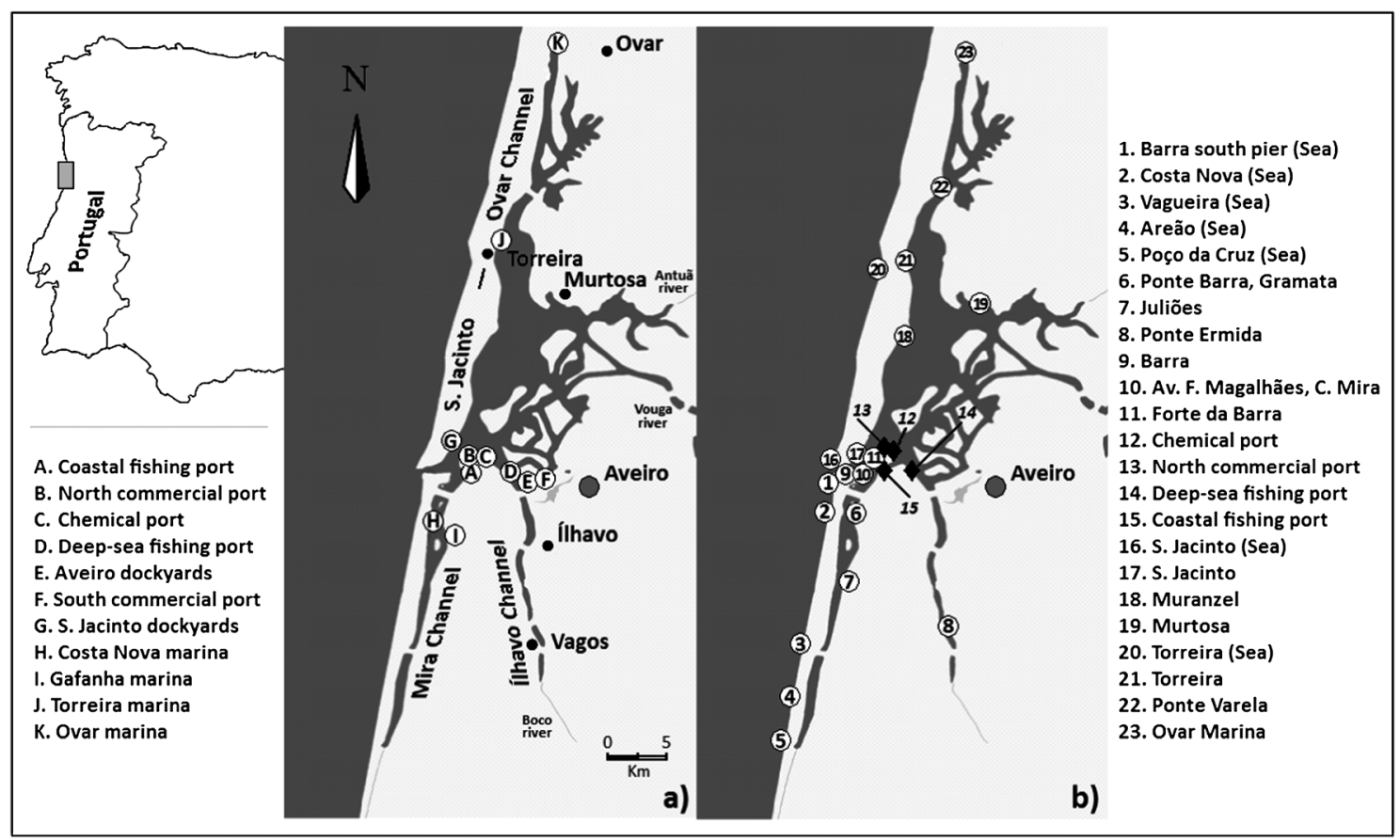

Fig. 1 Ria de Aveiro and adjacent coastal area map indicating: (a) main TBT pollution sources (A-K); (b) sampling sites (Sts.) location, code and name (1-23; $\bigcirc$ and $\bullet$, outside and inside port terminals, respectively). 


\section{Hexane-extractable tin concentrations in water}

Samples of 21 of sub-surface ( $15 \mathrm{~cm}$ depth) water were collected in two 11 glass bottles, previously washed in $0.5 \%$ hydrochloric acid $(\mathrm{HCl})$. Immediately before each sample collection, bottles were rinsed with local water. Afterwards, samples were acidified with $5 \mathrm{ml}$ concentrated $\mathrm{HCl}$ litre $^{-1}$. Methods used for extraction (from unfiltered water) and OT analysis are those described by Bryan et $a .^{8}$ providing a detection limit of about $0.2 \mathrm{ng} \mathrm{Sn} 1^{-1}$. However, washing of hexane extracts with $1 \mathrm{~N}$ sodium hydroxide $(\mathrm{NaOH})$ to separate DBT from the TBT fraction was not performed; hence we report values as hexane extractable tin, as we only aim to depict any recent OT inputs.

\section{Statistical data analysis}

SigmaStat v2.0 software was used to perform the statistical analysis of the data. The analysis of dog-whelk imposex evolution between 1997 and 2007, at Sts. 2, 3, 9 and 11 ("Long-term monitoring"), was performed using two different approaches depending on whether sampling sites were analysed together or separately. In the first approach, the subjects were the four sampling sites and the observations were the VDSI or the FPL at each site; the purpose of the analysis was to test if the VDSI and FPL of all four sites changed significantly over the 10 year period, using a Friedman test followed by the post-hoc Dunn's test for multi-comparisons. The second approach was applied to evaluate the change in imposex intensity at each site over the
10 year period. In this case the subjects were the females analysed per site and the observations were the VDS stage exhibited by each specimen, i.e. samples were assumed to be independent since specimens collected randomly over time were not the same; a non-parametric Kruskal Wallis test, followed by the post-hoc Dunn's test for multi-comparisons, was applied in this case. Statistical comparisons using RPSI were not performed because this index depends on $\mathrm{SH}$, which varied not only within but also between genders and in some cases in dissimilar directions.

The assessment of imposex evolution between 2005 and 2006 for the "Short-term monitoring" analysis was performed using the two different statistical approaches described above. Firstly, the subjects were the nine sampling sites and the observations were the VDSI or the FPL at each site; the purpose of the analysis was to test if the combined VDSI and FPL changed significantly within a single year, using a Wilcoxon signed-rank test. In the second approach, the Mann-Whitney U-test was applied to assess differences in VDS and PL in females at each site between 2005 and 2006 .

\section{Results}

\section{Long-term monitoring}

Nucella lapillus FPL, RPSI, VDSI and \%I observed in 1997 , 2003, 2005, 2006 and 2007 at Sts. 2, 3, 9 and 11 are registered in Table 1 . When sampling sites are analysed together, it is clearly

Table 1 Nucella lapillus imposex long-term monitoring. Male and female mean shell heights (mm), standard deviation (SD) and number of analysed specimens $(n)$ are presented in the format $\mathrm{mm} \pm \mathrm{SD}(n)$, per site and year. Indication of: mean female penis length (FPL), relative penis size index (RPSI), vas deferens sequence index (VDSI) and percentage of imposex affected females $(\% I)$. For additional data on site locations see Fig. 1

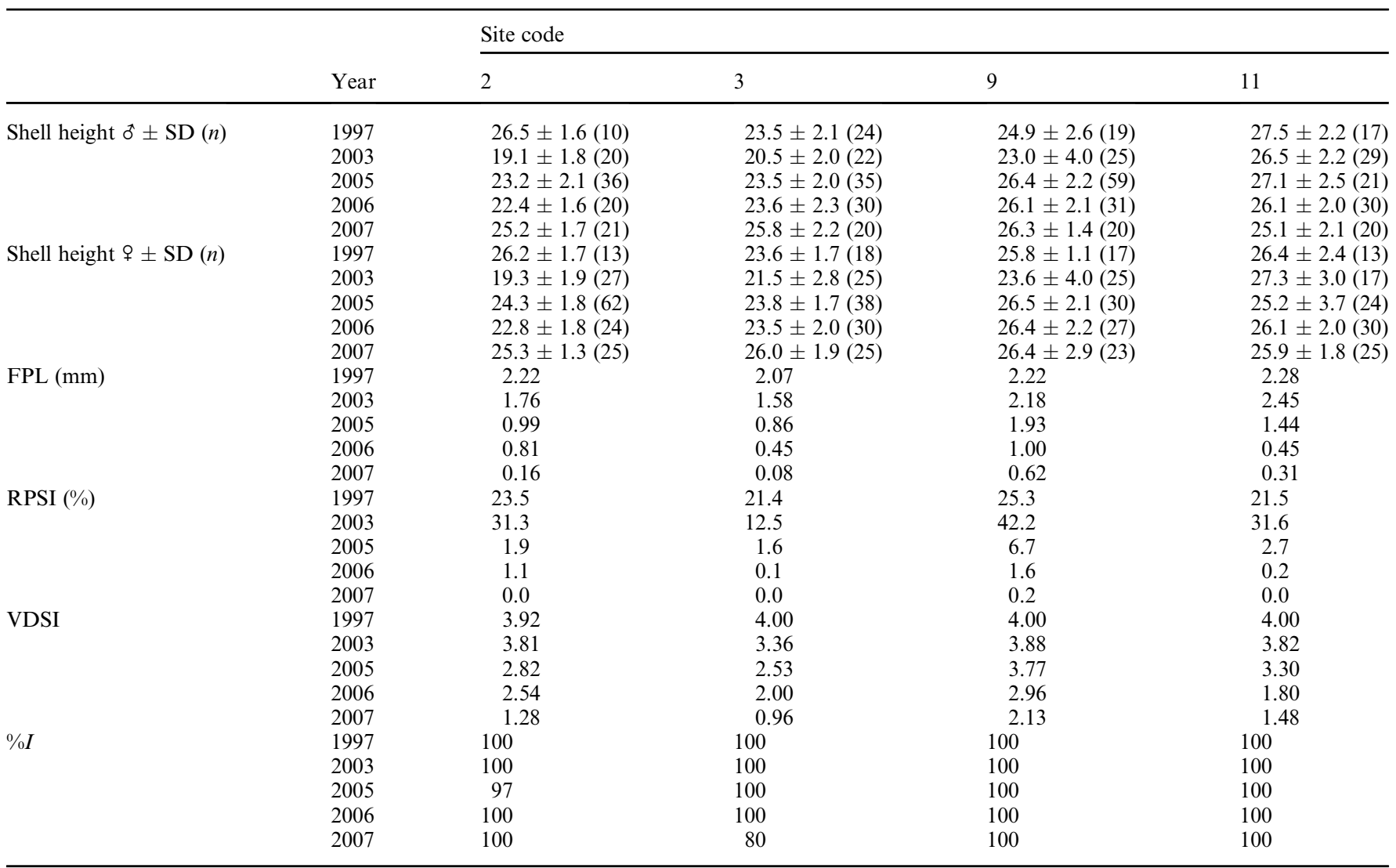



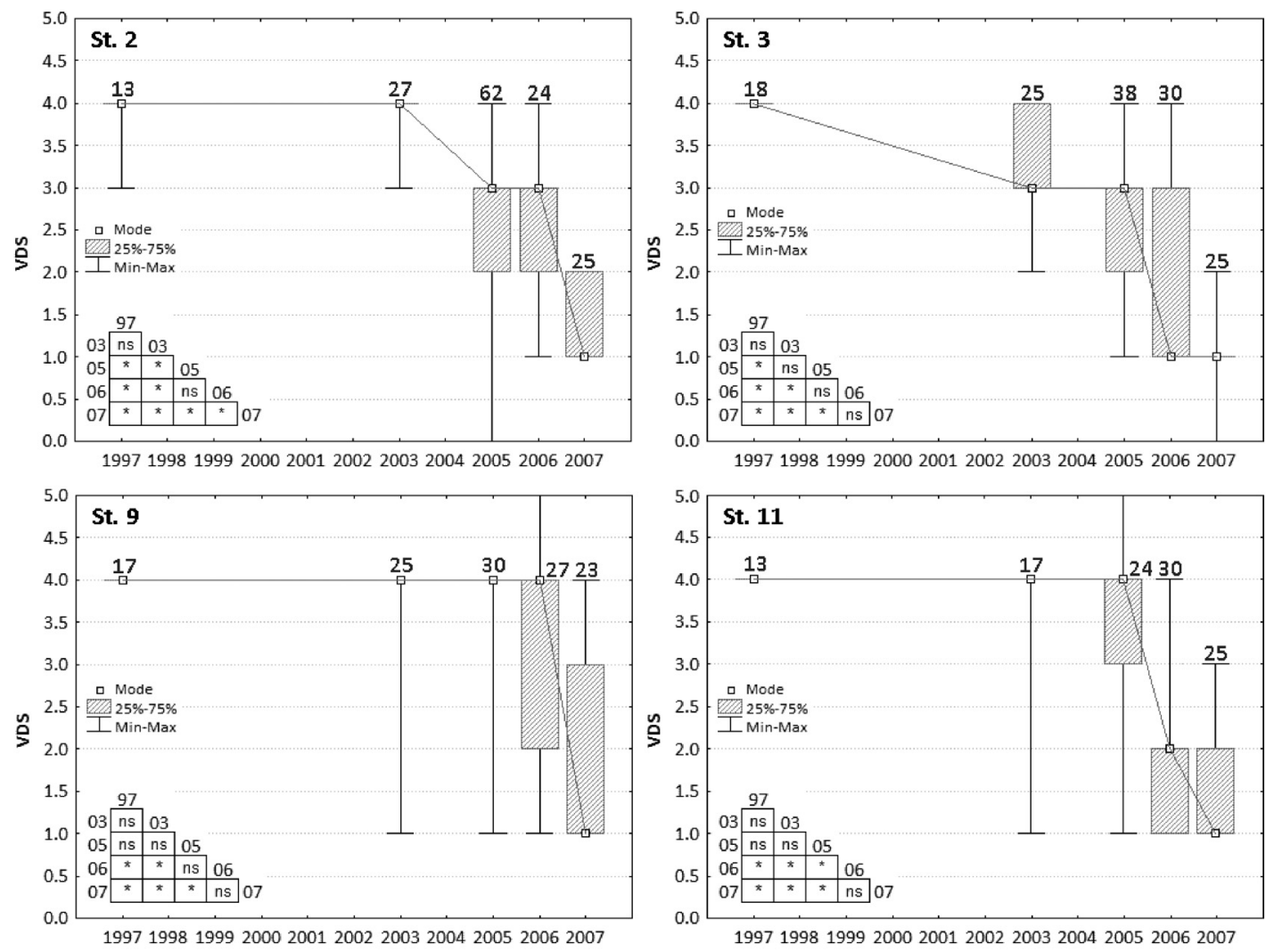

Fig. 2 Nucella lapillus long-term monitoring (separated sites). Temporal variation of imposex exhibited by specimens collected in the Ria de Aveiro (NW Portugal) at Sts. 2, 3, 9 and 11. For each site, the VDS mode, percentiles (25\%-75\%), minimum and maximum values (Min-Max) registered in 1997, 2003, 2005, 2006 and 2007 is indicated. The number of analysed specimens is shown above the respective median point. The significance of the Dunn's test for multi-comparisons between years is shown on the respective plot: ${ }^{*} p<0.05$; ns, not significant.

detected a general decline from 1997 to 2007 in both VDSI (Friedman's test: $s=16.000, p<0.01)$ and FPL $(s=15.400, p<$ 0.01). Dunn's multi-comparisons tests between different years show a significant reduction of VDSI and FPL levels from 1997 to 2007 and also of FPL from 2003 to 2007; the imposex decline was evident only after 2003. When females are analysed at each site, it is found a decrease in VDS along time (Fig. 2) at the four locations (Kruskal Wallis tests gave always significant differences with $p<0.001$ ). Multi-comparisons show that the imposex decline is evident from 2003 onwards and most marked between 2005 and 2007, being accompanied by an increase in the values dispersion (Fig. 2). However, a high percentage of females with imposex was observed, even in 2007, showing that it remains a common phenomenon in the study area.

\section{Short-term monitoring}

N. lapillus FPL, RPSI, VDSI and \%I observed in 2005 at Sts. 1-5, $9,11,16$ and 20 ranged between $0.28-1.93 \mathrm{~mm}, 0.0-8.7 \%, 1.43-$ 3.77 and $91-100 \%$, respectively. In 2006 the same indices varied between $0.10-1.00 \mathrm{~mm}, 0.0-1.6 \%, 0.71-2.96$ and $46-100 \%$ (Table 2). Combining all sites together, there was a significant reduction between 2005 and 2006 in both VDSI (Wilcoxon test: $W=$ $-45.000, p<0.01)$ and FPL $(W=-45.000, p<0.01)$. Similarly, the per site analysis indicates that females VDS and PL decreased in all sampling sites from 2005 to 2006, though the decline was significant only for about $2 / 3$ of the sites (see Table 2).

OTs concentrations in female $N$. lapillus tissues are also presented in Table 2. TBT concentrations varied from 10 to $126 \mathrm{ng}$ Sn $\mathrm{g}^{-1} \mathrm{dw}$ and a much higher proportion of TBT in relation to DBT was recorded. Hexane-extractable tin values in water are presented in Table 3 and were highly variable over the one week period between the two sampling occasions in 2006, probably as a consequence of the changeable hydrodynamic regime of this estuarine system. The arithmetic mean of values observed within a week interval at each site ranged from $<0.6$ to $38.5 \mathrm{ng} \mathrm{Sn} 1^{-1}$.

\section{Discussion}

OSPAR developed provisional assessment criteria for Nucella lapillus imposex. ${ }^{23}$ These criteria define 6 assessment classes (AF) through VDSI intervals (from VDSI $<0.3$ to VDSI $\geq 5$ ) that were developed taking into account the objectives of the OSPAR Hazardous Substances Strategy and the existing Ecotoxicological Assessment Criteria (EAC) for TBT in water (upper EAC

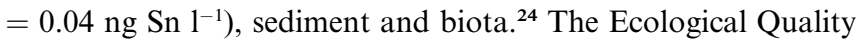
Objective (EcoQO) for imposex in $N$. lapillus corresponds to values lower than VDSI $=2$ (the limit between assessment classes $\mathrm{B}$ and C). ${ }^{23,24}$ In retrospect, the ecological quality of the Ria de Aveiro in 1997 (current study) and in 1998 (survey performed by 


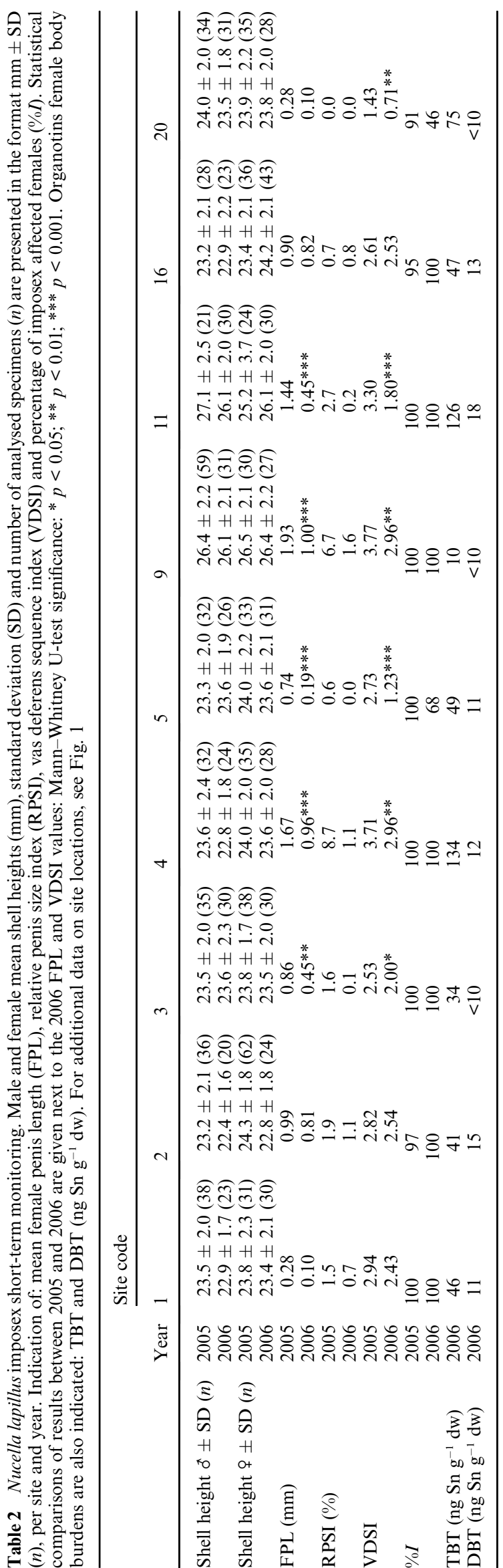

Table 3 Organotins in water (ng Sn $1^{-1}$ as hexane extractable tin) in 2006: values for two sampling occasions (1st and 2 nd samp) and the respective mean value is indicated. For additional data on sites location see Fig. 1

\begin{tabular}{lccr}
\hline & \multicolumn{2}{c}{ Hexane extractable tin/ng Sn $1^{-1}$} & \\
\cline { 2 - 4 } Site code & 1st samp & 2nd samp & Mean \\
\hline 1 & 1 & 4 & 2.5 \\
2 & 2 & 2 & 2.0 \\
3 & 1 & 3 & 2.0 \\
4 & 1 & 1 & 1.0 \\
5 & 1 & $<0.2$ & $<0.6$ \\
6 & 74 & 3 & 38.5 \\
7 & 4 & 7 & 5.5 \\
8 & 8 & 2 & 5.0 \\
9 & 1 & 6 & 3.5 \\
10 & 3 & 10 & 6.5 \\
11 & 37 & 1 & 19.0 \\
12 & 5 & 9 & 7.0 \\
13 & 3 & 4 & 3.5 \\
14 & 11 & 6 & 8.5 \\
15 & 7 & 13 & 10.0 \\
16 & 1 & 1 & 3.5 \\
17 & 4 & 3 & 2.5 \\
18 & 1 & 4 & 2.5 \\
19 & 2 & 3 & 2.0 \\
20 & 3 & 1 & 5.0 \\
21 & 9 & 1 & 4.5 \\
22 & 4 & 5 & 3.0 \\
23 & 5 & 1 & \\
\hline
\end{tabular}

Barroso et al. $)^{19}$ fall into class $\mathrm{D}(4.0 \leq \mathrm{VDSI} \leq 5.0)$ as $N$. lapillus exhibited VDSI between about 4.0 and 4.4 at all surveyed sites (2, $3,9,11$ and 12); it should be noted that sterile females were observed only at site 12 in 1998 but this population had probably become extinct afterwards as no animal could be found recently, namely during the 2005 and 2006 sampling campaigns. The present study shows that there was an evident decline in TBT pollution in the following years and in 2006/2007 the ecological status of the Ria de Aveiro had improved significantly (see Fig. 2) since the VDSI at the same sites dropped to values between 1.0 and 3.0, corresponding to the OSPAR classes B-C. The current study also shows that an imposex decline could be detected over a short period of time between 2005 and 2006, which suggests that TBT pollution is diminishing rapidly. As imposex in $N$. lapillus is an irreversible phenomenon, ${ }^{8}$ these results also suggest that the species has a high population renewal rate in the study area; i.e. older animals with higher levels of imposex are rapidly substituted by less affected younger ones. The temporal trend described above is corroborated by the amelioration of imposex in Nassarius reticulatus in the Ria de Aveiro between 2000 and $2005 .{ }^{21}$ Hence, in a decade, the ecological status of the Ria de Aveiro has changed considerably. The ecological enhancement of the ecosystem was accompanied by enrichment of the economical potential, confirmed by the example of the oyster production activities in the study area: in the 10 year period of this study, shell length measurements showed an increase of $36 \%$ in the oysters growth rate, accompanied by a $77 \%$ decrease in shells chambering (S. Galante-Oliveira, unpublished data)a phenomenon caused by exposure to TBT. ${ }^{25,26}$ According to the shellfish farmers, this amelioration was noted only after 2004 and 
has resulted in a two-fold net increase in export value (discounting inflation) of the oysters from 2004 to 2007.

It is important to analyse the possible causes for the recent decline in TBT pollution in the area, as these considerations are useful for future management of similar pollution problems elsewhere. It is known that the first ban on the use of AFP on small boats was ineffective in reducing TBT pollution along the Portuguese continental coast. ${ }^{11,12}$ In fact, the transposition of the 89/677/EEC Directive into national law occurred in 1993 but in $2000^{11}$ and $2003^{27} N$. lapillus populations were still severely affected by imposex along the coast and in 2003 a VDSI $\geq 4.0$ was still evident at $\sim 60 \%$ of the sampled sites. The very same pattern was also observed in the current study within the Ria de Aveiro (see Fig. 2). The major change in imposex levels in the Ria de Aveiro appears to have occurred only after 2003, which was coincident with the implementation of the EU Regulation no. $782 / 2003$. Specifically, our data show a statistically significant decline in the FPL in the successive surveys performed from 2003 to 2007 and a progressive significant decline of VDSI between 2005 and 2007. During the latter period, a decrease in the RPSI and $\% I$ was also evident. Hence, the main cause for this change was most probably the implementation of the EU Regulation no.782/2003 in 1 July 2003. It is important to stress that during this period there was no decrease of naval or commercial traffic calling at the Port of Aveiro, which suggests a decline in the use of TBT-based AFP by ships and/or a reduction of inputs from dockyards after the EU regulation. Interestingly, the proportion of ships that were entering into Aveiro's Port from countries where TBT could still be applied (from states outside the European Union and countries where the AFS Convention has not been ratified) also decreased from $50 \%$ in 2003 to $23 \%$ in 2005 and to $19 \%$ in 2007 (C. Oliveira, Aveiro's Port Administration, personal communication).

Despite the substantial recovery of $N$. lapillus imposex over the studied period, the VDSI level recorded at site 9 in 2007, located in the major traffic lane in the study area, still falls into class C. This fact indicates that at sites close to identified sources there is still a risk of adverse effects, such as reduced growth and recruitment in the most sensitive taxa of the ecosystem, caused by long-term exposure to TBT. Moreover, as imposex levels continue to be higher at sites located in the vicinity of maritime traffic lanes and port terminals (Sts. 9 and 11; Fig. 1 and 2), ships may still represent the major sources of TBT to the environment.

Further evidence that TBT pollution continues, despite the current amelioration, comes from the analysis of OTs in $N$. lapillus tissues and water. Recent contamination of $N$. lapillus is suggested by the high proportion of TBT in relation to DBT (primary degradation metabolite of TBT) in the tissues. Additionally, OTs were present in sub-surface waters with mean concentrations varying from $<0.6$ to $38.5 \mathrm{ng} \mathrm{Sn} 1^{-1}$, the major fraction of which is known to be TBT and DBT. These data are corroborated by prior descriptions of fresh TBT inputs in the study area: for the same period Sousa et al..$^{21}$ described a high proportion of TBT in sediments as well as in Nassarius reticulatus and Mytilus galloprovincialis tissues, in relation to the other BTs (DBT and monobutyltin-MBT). These fresh inputs were expected since TBT-based AFP legislation was not fully effective until September 2008. Furthermore, it is well documented that TBT is persistent within sediments, with half-lives in the range of years, ${ }^{1,28}$ and can be continuously released into the environment. ${ }^{29}$ Thus, $N$. lapillus may still accumulate TBT from the above contamination sources. Nevertheless, if imposex decline in $N$. lapillus observed in the recent years continues at a similar rate in the future (see Fig. 2) it is predicted that the phenomenon might reach almost undetectable levels by the beginning of next decade.

\section{Conclusions}

The current study shows that all $N$. lapillus populations in the study area are extensively affected by imposex and there are still recent inputs of TBT into this estuarine system. Nevertheless, we observed a general reduction in TBT pollution in the last 10 years. This decline was mainly noticed after 2005 , for which the EU Council Regulation no.782/2003 was certainly determinant. The ecological status of the Ria has improved, confirming the effectiveness of legislation and demonstrating benefits in an estuarine system where the maintenance of environmental quality is highly important.

\section{Acknowledgements}

The authors are deeply grateful to: the assistance of Raquel Quintã, Nelson Ferreira and Ionut Marcovici during sampling campaigns; local oyster farm owners and their willingness in providing the oyster culture data information; Carlos Oliveira from APA (Administração do Porto de Aveiro) for the kindness in supplying the Aveiro Port statistics. This work was supported through a PhD grant to Susana Galante-Oliveira (SFRH/BD/ 18411/2004) attributed by the Portuguese Foundation for Science and Technology (FCT) founded by the Portuguese Government and the research project POCI/MAR/61893/2004 financed by the FCT and by the POCI 2010, co-financed by FEDER.

\section{References}

1 S. J. de Mora, in Tributyltin: Case Study of an Environmental Contaminant, ed. S. J. de Mora, Cambridge University Press, Cambridge, Environmental Chemistry Series no. 8, 1996, ch. 1, pp. $1-13$.

2 B. S. Smith, Proceedings of the Malacological Society of London, 1971, 39, 377-378

3 B. S. Smith, J. Appl. Toxicol., 1981, 1, 141-144.

4 A. C. Birchenough, S. M. Evans, C. Moss and R. Welch, Mar. Pollut. Bull., 2002, 44, 652-659.

5 JAMP, Guidelines for contaminant specific biological effects monitoring, Ref. No. 1998-3, OSPAR Commission, London, 1998.

6 J. H. Crothers, Field Stud., 1985, 6, 291-360.

7 P. E. Gibbs and G. W. Bryan, Oceans' 87 Proceedings, International Organotin Symposium, vol. 4, pp. 1482-1487, 1987.

8 G. W. Bryan, P. E. Gibbs, L. G. Hummerstone and G. R. Burt, J. Mar. Biol. Assoc. UK, 1986, 66, 611-640.

9 P. E. Gibbs and G. W. Bryan, J. Mar. Biol. Assoc. UK, 1986, 66, $767-$ 777.

10 EC Official Journal, Directive 89/677/EEC, Ref. No. OJ L 398, pp. 24, 1989.

11 C. M. Barroso and M. H. Moreira, Mar. Pollut. Bull., 2002, 44, 480486.

12 M. M. Santos, C. C. Ten Hallers-Tjabbes, A. M. Santos and N. Vieira, J. Sea Res., 2002, 48, 217-223. 
13 MEPC, International Convention on the Control of Harmful AntiFouling Systems on Ships (AFS Convention), Ref. No. AFS/CONF/ 26, IMO, London, 2001.

14 EC Official Journal, Directive 2002/62/EC, Ref. No. OJ L 183, pp. 58, 2002.

15 EC Official Journal, Regulation No.782/2003, Ref. No. OJ L 115, pp. 1, 2003.

16 Summary of Conventions as at 30th November, available from http:// www.imo.org/, online, cited 10th December 2007, IMO, London, 2007.

17 C. B. Lopes, M. E. Pereira, C. Vale, I. LillebØ, M. A. Pardal and A. C. Duarte, Sci. Mar., 2007, 71, 293-304.

18 P. E. Gibbs, G. W. Bryan, P. L. Pascoe and G. R. Burt, J. Mar. Biol. Assoc. UK, 1987, 67, 507-523.

19 C. M. Barroso, M. H. Moreira and P. E. Gibbs, Mar. Ecol. Prog. Ser., 2000, 201, 221-232.

20 M. Rato, A. Sousa, R. Quintã, W. Langston and C. Barroso, Environ. Toxicol. Chem., 2006, 25, 3213-3220.

21 A. Sousa, C. Matsudaira, S. Takahashi, S. Tanabe and C. M. Barroso, Mar. Pollut. Bull., 2007, 54, 1645-1653.
22 G. S. Ward, G. C. Cramm, P. R. Parrish, H. Trachman and A. Slesinger, in Aquatic Toxicology and Hazard Assessment: Fourth Conference, eds. D. R. Branson and K. L. Dickson, Associate Committee on Scientific Criteria for Environmental Quality, Pennsylvania, 1981, pp. 183-200.

23 JAMP, Assessment Criteria for TBT-Specific Biological Effects, Ref. No. 2004-15, OSPAR Commission, London, 2004.

24 JAMP, Agreed ecotoxicological assessment criteria for trace metals, PCBs, PAHs, TBT and some organochlorine pesticides, Ref. No. 1997-15, OSPAR Commission, London, 1997.

25 C. L. Alzieu, J. Sanjuan, J. P. Deltreil and M. Borel, Mar. Pollut. Bull., 1986, 17, 494- 498.

26 D. Chagot, C. L. Alzieu, J. Sanjuan and H. Grizel, Aquat. Living Resour., 1990, 3, 121-130.

27 S. Galante-Oliveira, W. J. Langston, G. R. Burt, M. E. Pereira and C. M. Barroso, Appl. Organomet. Chem., 2006, 20, 1-4.

28 K. Saeki, A. Nabeshima, T. Kunito and Y. Oshima, Chemosphere, 2007, 68, 1114-1119.

29 M. A. Sheikh, K. Tsuha, X. Wang, K. Sawano, S. T. Imo and T. Oomori, Int. J. Environ. Anal. Chem., 2007, 87, 847-861. 